LIAMES 4 - pp. 103-113, Primavera 2004

Mônica Veloso Borges

(UFG / PG-UNICAMP)

\title{
Diferenças entre as falas feminina e masculina no Karajá e em outras línguas brasileiras: aspectos tipológicos
}

\section{RESUMO}

O Karajá (Família Karajá) é falado por aproximadamente dois mil indígenas (em Goiás, Mato Grosso e Tocantins). Essa língua possui distinções, conforme o sexo do falante, no nível fonético-fonológico, as quais foram descritas por Borges (1997), tais como: a) distinções no ataque de uma ou duas sílabas; b) diferenças no ataque e no núcleo de uma sílaba medial; e c) diferença nos segmentos que compõem as sílabas. As distinções entre as falas do homem e da mulher podem ser encontradas também em empréstimos tomados ao português. Nesse trabalho são apresentadas essas diferenças e são discutidos dados de outras línguas brasileiras, tais como Xavante (também Macro-Jê). A conclusão é que as diferenças entre as falas, no Karajá, parecem ser distintas das que ocorrem em outras línguas brasileiras, que, quando manifestam esse fenômeno, têm distinções mais marcadas no nível morfossintático, como o Kamayurá e o Kokáma (ambas da Família Tupi-Guarani), e em Xavante.

PALAVRAS-CHAVE Karajá; fala masculina; fala feminina; Empréstimos.

\section{RESUMEN}

La lengua Karajá (familia Karajá) es hablada por aproximadamente dos mil indígenas (en Goiás, Mato Grosso e Tocantins). Esa lengua tiene posee distinciones, según el sexo del hablante, en el nivel fonético-fonológico, las cuales fueron descriptas por Borges (1997), tales como: a) distinciones en el ataque de una o dos sílabas; b) diferencias en el ataque y en el núcleo de una sílaba medial; y c) diferencia en los segmentos que componen las sílabas. Las distinciones entre el habla del hombre y de la mujer pueden encontrarse también en préstamos tomados al Portugués. En ese trabajo son presentadas esas diferencias y son discutidos datos de otras lenguas brasileñas, tales como Xavante (Macro-Jê). La conclusión es que las diferencias entre las hablas, en Karajá, parecen ser distintas de las que ocurren en otras lenguas indígenas brasileñas que, cuando manifiestan ese fenómeno, tienen distinciones más marcadas en el nivel morfo-sintáctico, como es el caso del Kamayurá y del Kokáma (ambas, Família Tupi-Guarani), y en Xavante.

Palabras Llaves Karajá; habla masculina; habla femenina; Prestamos. 
104

\section{INTRODUÇÃO}

Há vários estudos atualmente que comprovam que quase todas as línguas do mundo, em maior ou menor grau, estabelecem distinção entre as falas feminina e masculina, principalmente, no que diz respeito ao léxico, havendo, no mínimo, duas formas distintas para designar-se o mesmo objeto, dependendo do sexo do locutor, do interlocutor, de ambos, ou da pessoa sobre a qual se fala (Bodine, 1991). Contudo, são as línguas indígenas as que demonstram de forma mais categórica essa oposição, que pode se manifestar nos níveis fonético, fonológico, morfossintático, semântico e discursivo (Balmori, 1967).

De acordo com Bodine (op. cit.), a distinção entre as falas baseadas no sexo do locutor foi bastante divulgada nos séculos XVII e XVIII. O exemplo clássico freqüente e erroneamente mencionado é o da língua Caraíba. Segundo Rochefort (1665, apud Jespersen, 1921), quando os Karibe ocuparam as Pequenas Antilhas, estas eram habitadas por tribos Arawak, que foram exterminadas, à exceção das mulheres, com quem eles se casaram para povoar a região. Elas mantiveram suas línguas, transmitindo-as a suas filhas. Os meninos, por sua vez, embora entendessem a fala de suas mães e irmãs, falavam a língua de seus pais e irmãos. Desse modo, não se tratava de modalidades diferentes de uma mesma língua, mas, ao contrário, de línguas distintas.

A seguir apresento o fenômeno da diferenciação entre as falas feminina e masculina em cinco línguas indígenas brasileiras, a saber: Kamaiurá, Karajá, Kokáma, Pirahã e Xavante ${ }^{1}$.

\section{KAMAIURÁ}

A língua Kamaiurá, pertencente à família Tupi-Guarani, possui posposições restritas a homens e mulheres. No entanto, seu significado ainda será melhor explorado em trabalhos futuros (Lucy Seki, em comunicação pessoal). Conforme Seki (2000), a'e e wa, exemplificadas abaixo, são apenas algumas das posposições distintas para os $\operatorname{sexos}^{2}$.

(1) ã: /w-eraha rake ta'yj-a kor=a'e

intj /3-levar AT menina-N FS=/FM

oh! ela levou a menina

(2) o'iran já-ko -apy korina'e=wa

amanhã 1pi-roça-queimar FUT Nint = MS

amanhã queimaremos nossa roça

\footnotetext{
${ }_{2}^{1}$ As classificações lingüísticas utilizadas neste artigo são as de Rodrigues (1986).

${ }^{2}$ As abreviaturas e convenções utilizados nos exemplos do Kamaiurá são: intj interrogativo, / pausa, $33^{\text {a }}$ pessoa, AT atestado, N caso nuclear, FS fim de sentença, FM falante do sexo feminino, = fronteira de clítico, $11^{\text {a }}$ pessoa, pi pessoa inclusiva, FUT futuro, Nint não interrogativo, MS falante do sexo masculino.
} 


\section{KARAJÁ}

O Karajá, pertencente ao tronco Macro-Jê e à família Karajá, que é falado no Brasil por aproximadamente dois mil indígenas, nos Estados de Goiás, Mato Grosso e Tocantins, possui formas femininas e masculinas distintas baseadas principalmente no sexo do falante. De acordo com Borges (1997), essa língua possui as seguintes diferenças entre as falas feminina e masculina, referentes ao nível fonológico.

(3) Diferença no onset de uma sílaba

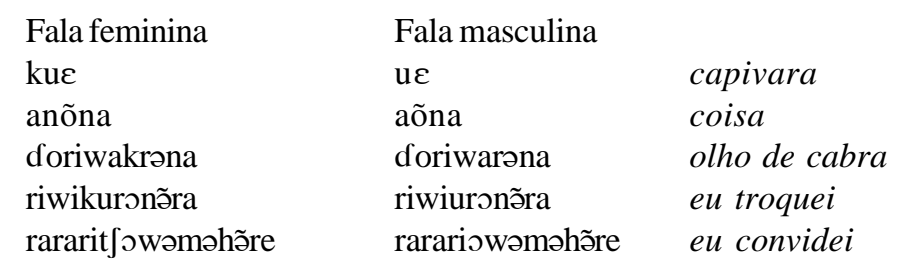

Percebe-se nesses itens lexicais que as formas femininas possuem uma unidade temporal a mais do que as masculinas correspondentes. Essa unidade temporal diz respeito às consoantes oclusiva velar desvozeada $/ \mathrm{k} /$, nasal dental vozeada $/ \mathrm{n} /$ e africada palatoalveolar desvozeada /t $\mathrm{f} /$, em início de sílabas mediais. Atente-se para o fato de que $\mathrm{o} / \mathrm{n} / \mathrm{da}$ fala feminina acontece entre as vogais central baixa /a/ e posterior média nasal /õ/. O /t $\mathrm{f} /$, por sua vez, ocorre na fala das mulheres entre as vogais anterior alta $/ \mathrm{i} / \mathrm{e}$ central baixa $/ \mathrm{a} / \mathrm{ou}$ posterior média / $/$. Já a oclusiva $/ \mathrm{k} /$ pode ainda realizar-se apenas na fala feminina no início de itens lexicais.

(4) Diferença nos onsets de duas sílabas

$\begin{array}{lll}\text { Fala feminina } & \text { Fala masculina } & \\ \text { anõmaks } & \text { aõmas } & \text { para aquele lado } \\ \text { werikəkっ } & \text { werios } & \text { cachimbo } \\ \text { raritfakõreri } & \text { rariaõreri } & \text { ele (a) não está andando }\end{array}$

Quando os itens lexicais das duas falas diferem com relação aos onsets de duas sílabas, nota-se que o segundo deles é preenchido pela consoante /k/. Por outro lado, o primeiro onset pode ser ocupado pelas consoantes $/ \mathrm{k} /, \mathrm{ln} / \mathrm{e} / \mathrm{t} \mathrm{J} /$, nessa ordem de preferência.

(5) Diferença no núcleo de uma sílaba e no onset da sílaba seguinte

Fala feminina Fala masculina

helikõre helãre pato

wakəronə) worวñ̃ urucum 
Esses itens lexicais diferenciam-se porque as formas femininas possuem um núcleo e um onset contíguos a mais do que as formas masculinas correspondentes. Esse onset é composto pelo / $/ \mathrm{e}$ e o núcleo pelas vogais centrais alta /i/ e baixa /a/, as quais são seguidas por uma sílaba cujo núcleo é formado pelas vogais médias central nasal /â/ e posterior /o/, respectivamente.

(6) Diferença no núcleo de uma sílaba e no onset da sílaba seguinte e, ainda, em outro onset
Fala feminina
Fala masculina
rakodukoreri
roduoreri
eu estou subindo

A forma feminina/rakodukoreri/ distingue-se de /roduoreri/ no que concerne a um núcleo e um onset adjacentes, formados, respectivamente, pela vogal /a/ e pela consoante $/ \mathrm{k} /$. O outro onset que ocorre somente na fala feminina é do mesmo modo preenchido pela consoante mencionada.

(7) Diferença no onset e no núcleo de sílaba final

$\begin{array}{lll}\text { Fala feminina } & \text { Fala masculina } & \\ \text { ikoku } & \text { iko } & \text { adiante } \\ \text { hawoko } & \text { hawo } & \text { canoa } \\ \text { dzuhuku } & \text { dzuhu } & \text { antigamente } \\ \text { bəderahiki } & \text { bəderahi } & \text { mato } \text { (substantivo) } \\ \text { wahitjiwoku } & \text { wahitjiwo } & \text { meus rins }\end{array}$

Nesses itens lexicais comprova-se a existência de uma sílaba CV final a mais na fala das mulheres, sílaba essa em que o onset é preenchido pela oclusiva velar desvozeada $/ \mathrm{k} /$ e o núcleo pelas vogais posteriores alta /u/ e média /o/ e pela central alta /ił/. Precedem o /u/ as vogais posteriores médias $/ \mathrm{o} / \mathrm{e} / \mathrm{J} / \mathrm{e}$ a alta $/ \mathrm{u} /$. Por seu turno, as vogais central alta $/ \mathrm{i} / \mathrm{e}$ posterior média $/ \mathrm{s} /$ são antecedidas por vogais idênticas a elas.

(8) Diferença no onset de uma sílaba e no onset e no núcleo de uma sílaba medial ou final

$\begin{array}{lll}\text { Fala feminina } & \text { Fala masculina } & \\ \text { kolokuna } & \text { olona } & \text { pena branca } \\ \text { ikoloku } & \text { iolo } & \text { rei } \\ \text { koworuku } & \text { oworu } & \text { roça }\end{array}$

Os itens lexicais previamente vistos demonstram que as formas femininas contêm uma sílaba CV medial ou final a mais do que as formas masculinas correspondentes. Essa sílaba tem um onset e um núcleo compostos, respectivamente, por /k/ e /u/. Antecedem essa sílaba as vogais posteriores alta /u/ e média aberta / /. O outro onset que aparece exclusivamente na fala feminina é também constituído pela referida consoante. 
107

(9) Diferença no onset e no núcleo de uma sílaba medial e no onset de uma sílaba seguinte

$\begin{array}{lll}\text { Fala feminina } & \text { Fala masculina } & \\ \text { wakowikっ } & \text { wawiı } & \text { vinte } \\ \text { rawokudəkə̃nə̃məhə̃reri } & \text { rawodəãnə̃məhə̃reri } & \text { ele(a) está fazendo barulho }\end{array}$

Nos dois exemplos apontados em (9), verifica-se que as formas femininas possuem três unidades temporais a mais do que as masculinas. As primeiras têm uma sílaba CV medial e um onset que não são encontrados nas últimas. Esse onset é ocupado pela consoante $/ \mathrm{k} /$. A sílaba presente apenas na fala feminina, por sua vez, tem por constituintes esta mesma consoante e as vogais posteriores $/ \mathrm{u} / \mathrm{e} / \mathrm{o} /$, antecedidas por $/ \mathrm{o} / \mathrm{e} / \mathrm{a} /$, nessa ordem.

(10) Diferença no onset e no núcleo de uma sílaba medial

\begin{tabular}{|c|c|c|}
\hline $\begin{array}{l}\text { Fala feminina } \\
\text { reakara }\end{array}$ & $\begin{array}{l}\text { Fala masculina } \\
\text { reara }\end{array}$ & eu fui \\
\hline 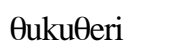 & OuӨeri & bigode \\
\hline ladekowo & ladewo & angico \\
\hline idzad॰koma & idzadoma & $m o c ̧ a$ \\
\hline dłkikirurena & dirurena & agulha \\
\hline wawokud $\varepsilon \theta \varepsilon$ & wawod $\varepsilon \theta \varepsilon$ & dor de barriga \\
\hline
\end{tabular}

Conforme indicam esses itens lexicais, as formas femininas assinalam uma sílaba CV medial a mais do que as masculinas equivalentes, na qual o onset é ocupado pela oclusiva velar desvozeada $/ \mathrm{k} /$ e o núcleo pelas vogais centrais /i/ e /a/ e posteriores $/ \mathrm{u} / \mathrm{e} / \mathrm{o} /$. As sílabas ki são antecedidas pela vogal /ił/, ao passo que a sílaba ka é precedida por /a/. A sílaba ko, por outro lado, pode ser antecedida pelas vogais médias abertas $/ \varepsilon / \mathrm{e} / \mathrm{\jmath} /$. No que tange às sílabas ku, estas são precedidas pelas vogais posteriores $/ \mathrm{u} / \mathrm{e} / \mathrm{o} /$.

(11) Substituição de uma sílaba CCV da fala feminina por uma $\mathrm{V}$, seguida de CV, na masculina

$\begin{array}{lll}\text { Fala feminina } & \text { Fala masculina } & \\ \text { krakre } & \text { arakre } & \text { eu vou embora } \\ \text { kralahu } & \text { aralahu } & \text { povo Kayapó }\end{array}$

Em alguns itens lexicais da fala feminina, uma sílaba inicial complexa $\mathrm{CCV}$, com onset complexo formado pelas consoantes $/ \mathrm{k} / \mathrm{e} / \mathrm{r} /$, realiza-se na fala masculina como duas sílabas, uma simples V e uma complexa CV. Nestes casos, a fala masculina evidencia uma sílaba a mais do que a feminina. Contudo, não se registram diferenças no número de unidades temporais dos itens lexicais, como atestam os exemplos em (11). Observe-se que é a vogal central baixa /a/ que ocupa o núcleo das sílabas CCV, na fala das mulheres, e V, seguida de $\mathrm{CV}$, na dos homens. 
Em suma, no Karajá alguns itens lexicais da fala das mulheres possuem até três unidades temporais a mais do que seus correspondentes na fala dos homens, como em /rẽ $\mathbf{k}$ / (fala feminina) e /rẽs/ (fala masculina) 'baru', que possuem quatro e três unidades temporais, respectivamente, já que o primeiro tem um onset a mais do que o segundo. Em outros casos, o número de unidades temporais dos itens lexicais de ambas as falas coincide, mas há mudanças de modo e ponto de articulação em um dos onsets, como se verifica em /wekirì/ (fala feminina) e /weriri/ (fala masculina) 'menino', ambos com seis unidades temporais cada, distinguindo-se porque /wekiri/ tem por segundo onset a oclusiva velar desvozeada /k/, a qual corresponde à vibrante simples alveolar/r/, na fala masculina.

Existem também exemplos nos quais as formas femininas e masculinas diferem pela

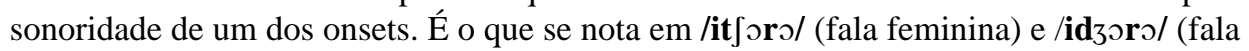
masculina) 'raposa', onde o onset da segunda sílaba é composto, na fala das mulheres, de o primeiro conter uma sílaba CV medial ku a mais do que o segundo, assim como pelas vogais que compõem os primeiros núcleos: a central baixa /a/ da fala feminina corresponde à posterior média fechada $/ \mathrm{o} /$. Em contrapartida, muitos itens lexicais do Karajá, especialmente alguns pronomes e advérbios, não assinalam quaisquer oposições entre as falas feminina e masculina, como atestam os itens lexicais /kai/ 'você', /kõre/ 'não' e /id3z/ 'espécie de concha'.

Essas diferenças entre as falas no Karajá são estabelecidas inclusive nos itens lexicais emprestados do português, como comprovam os dados a seguir:

$\begin{array}{llll}\text { (12) } & \text { Português } & \text { fala feminina } & \text { fala masculina } \\ \text { prego } & \text { /pregu/ } & \text { breku } & \text { breu } \\ \text { manga } & \text { /mãga/ } & \text { mãka } & \text { mãa } \\ \text { comprar } & \text { /kõprar/ } & \text { rekõbranãra } & \text { reõbranãra }\end{array}$

Confrontando os sistemas fonológicos do português e do Karajá, constata-se que ambos possuem a oclusiva velar desvozeada $/ \mathrm{k} /$. Porém, no que tange à sua homorgânica vozeada /g/, verifica-se sua ausência nessa língua indígena, em que a única oclusiva velar é desvozeada ou seja, $/ \mathrm{k} /$. Dessa maneira, nos itens lexicais emprestados do português, a consoante $/ \mathrm{k} /$ realiza-se muitas vezes no Karajá exclusivamente na fala feminina, sendo omitida na masculina, como demonstram os itens lexicais correspondentes a "comprar". Em contrapartida, a oclusiva velar vozeada /g/ normalmente torna-se desvozeada, ou seja, /k/, nas formas femininas do Karajá, desaparecendo nas masculinas correspondentes, como ocorre com os itens lexicais para "prego" $e$ "manga".

Desde as primeiras interações verbais com os filhos, os pais Karajá estabelecem a diferenciação na fala, conforme as normas para cada sexo. Desse modo, a mãe, a tia e a avó, que formam o grupo doméstico feminino, conversam com suas filhas, sobrinhas e netas na fala feminina, enquanto que com seus filhos, sobrinhos e netos falam na masculina. $\mathrm{O}$ mesmo ocorre com os pais, tios e avós, grupo doméstico masculino, que usam as formas femininas ao se comunicarem com as meninas e as masculinas quando conversam com os meninos. Esse procedimento objetiva mostrar às crianças, desde cedo, essa diferenciação entre as falas da mulher e do homem. Assim, os grupos domésticos feminino e masculino constituem-se em referências lingüísticas para as meninas e os meninos, nessa ordem. 
Quando da aquisição da língua Karajá, todos os membros dos grupos domésticos orientam as crianças no tocante às formas que elas deverão utilizar. Além de comunicarem-se com as meninas na fala feminina e com os meninos na masculina, os integrantes daqueles grupos também chamam a atenção das crianças ‘corrigindo' sua fala e mostrando-lhes que falam com elas de acordo com as normas lingüísticas estabelecidas para cada sexo. Nesse caso, homens e mulheres usam a fala feminina ao falarem com as meninas e a masculina ao se comunicarem com os meninos, o que mostra que os membros dessa sociedade indígena estão familiarizados tanto com a fala feminina quanto com a masculina, uma vez que usam ambas ao falarem com seus filhos. Portanto, a diferenciação entre as falas feminina e masculina no Karajá baseia-se nos sexos do locutor e do interlocutor. Uma outra situação em que os Karajá empregam a fala do sexo oposto é quando repetem um comentário de alguém ou quando narram histórias. Nesses casos, as falas dos personagens são mantidas na íntegra pelo narrador, independentemente de ele ser homem ou mulher. Assim, mesmo se o narrador for masculino manterá as falas dos personagens como no original, falando como homem quando se trata de personagem masculino e como mulher quando se trata de personagem feminino.

A distinção entre as falas feminina e masculina no Karajá insere-se num conjunto maior de oposições que polarizam a sociedade Karajá, relacionando-se a outras instituições para manter a distância social entre os sexos. Assim, um dos princípios ordenativos dessa sociedade indígena é a dicotomia homens/mulheres, sendo a diferença entre as falas um reflexo lingüístico desse princípio. Há, por conseguinte, uma relação entre essa estrutura social e o tipo de formas lingüísticas a serem usadas pelos falantes. Além de terem espaços reservados nas aldeias, homens e mulheres Karajá distinguem-se por usar pinturas corporais distintas, como o wariri $^{3}$ e o ibinõriti ${ }^{4}$, feitas em homens e mulheres, respectivamente, bem como por confeccionarem diferentes tipos de bonecas. As mulheres fazem bonecas em cerâmica, as ritxoko/ritxoo (falas feminina e masculina, respectivamente), ao passo que os homens confeccionam suas bonecas em madeira, as quais são denominadas de kawa kawa/awa awa (falas feminina e masculina, nessa ordem). No que se refere às cestas, há alguns tipos executados apenas pelos homens, como a behyra, que só eles utilizam, e outros feitos somente pelas mulheres. Este é o caso das ruri espiraladas. Há ainda cestas, como as ruri do mato, que são feitas por homens e mulheres, desde a mais tenra idade. A cesta wèriri, por sua vez, que só é manufaturada pelos homens, é usada por indígenas de ambos os sexos.

\section{KOKÁMA}

Uma outra língua a demonstrar a diferenciação entre as falas feminina e masculina é o Kokáma, da família Tupi-Guarani, falado no Estado do Amazonas, na fronteira com a Colômbia. Ela apresenta, de acordo com Faust (apud Balmori, op. cit.), formas especiais de pronomes para homens e mulheres, como atestam os seguintes exemplos.

\footnotetext{
${ }^{3} \mathrm{O}$ wariri é uma pintura usada pelos homens, nas costas, nas coxas e nas regiões epigástrica e abdominal.

${ }^{4} \mathrm{O}$ ibinõriti, 'desenho de umbigo', é usado por mulheres, na região abdominal, circunscrevendo o umbigo.
} 
110

(13) homens

$\begin{array}{lll}\text { homens } & \text { mulheres } & \\ \text { yucá } & \text { yucun } & \text { esse } \\ \text { ta } & \text { etse } & \text { eu, } \text { a mim } \\ \text { uri } & \text { ai } & \text { ele, } \text { a ele } \\ \text { tana } & \text { penu } & \text { nós, } \text { a nós }(\text { exclusivo) } \\ \text { rana } & \text { inu } & \text { eles, } \text { a eles }\end{array}$

Nota-se, em alguns casos, que uma mesma forma pronominal em Kokáma pode ser empregada, tanto por homens quanto por mulheres, conforme se segue.

(14) homens mulheres

$\begin{array}{lll}\text { ene } & \text { ene } & t u, a \text { ti, você, } a \text { você } \\ \text { ini } & \text { ini } & \text { nós, } a \text { nós }(\text { inclusivo) } \\ \text { epe } & \text { epe } & \text { vocês, } a \text { vocês }\end{array}$

Nessa mesma língua há também diferenças notáveis entre a fala da mulher e a do homem, no que diz respeito à fonética. Assim, 'de lá vim para cá' possui duas formas: a feminina, que é YAEPETSUI TSURIUI AYANGA, e a masculina RAEPETSUI TURIUI IQUIACA $^{5}$ (Balmori, op. cit.).

A língua Kayabi, também da família Tupi-Guarani, do mesmo modo que o Kokáma, possui distinções quanto às formas pronominais usadas por homens e mulheres (cf. Dobson, 1988). No entanto, essas diferenças não ficam claras no trabalho citado.

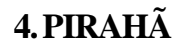

A língua Pirahã, pertencente à família Múra, falada no Brasil, estabelece distinções entre a fala da mulher e a do homem, as quais se evidenciam no nível fonético. Segundo Everett (1979), os alofones [1] e [b], dos fonemas /g/ e /b/, respectivamente, são mais recorrentes na fala das mulheres que na dos homens. A partir do registro de [1] e [b] na fala das mulheres, o autor formula a hipótese de que os comentários depreciativos dos nãoindígenas inibem o emprego desses segmentos, fazendo com que haja a substituição deles por outros segmentos possíveis no mesmo ambiente fonológico. Ele acrescenta que as mulheres raramente falam na presença de estranhos, nem tampouco falam com eles, o que as torna menos vulneráveis à pressão de escolher [g] e [b], ao invés de [1] e [b].

\footnotetext{
${ }^{5}$ As letras maiúsculas foram aqui usadas para que os exemplos apresentados fossem transcritos de
} forma fiel ao trabalho original de Balmori, em que aparecem sempre escritos dessa maneira. 
Everett (op. cit.) propõe, então, o traço [superstrato] ao qual se ligam dois pares de traços situacionais, a saber: [+mulher] e [-mulher] e [+familiar] e [-familiar] para distinguir [1] e [b], ambos [-superstrato], de [g] e [b], que são [+superstrato]. De acordo com esse autor, uma vez que, pelo menos aparentemente, os homens Pirahã dão maior valor à aprovação dos não-indígenas do que as mulheres, eles "estão menos dispostos a causar estranheza junto aos mesmos por selecionar um traço [-superstrato] quando existe um segmento [+superstrato] que serve no mesmo ambiente" (Everett, op. cit., 111). A seguir são ilustrados os alofones [1] e [ந] na língua Pirahã.

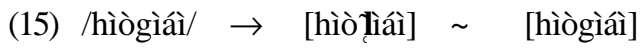
grande
(16) /íbòg/
$\rightarrow$ ['íbòtị]
['íbògì] ['íbògí]
leite
(17) /'ààbòì/ $\rightarrow$ ['ààbòì] ['ààbòì]
lagoa

Quanto à natureza fonética de [1] e [ந], fazem-se necessárias as seguintes elucidações: $1^{\circ}$ ) [1] é um flepe duplo ápico-alveolar sublâmino labial egressivo sonoro lateralizado com ar pulmonar expirado, "no qual o ápice da língua toca na arcada alveolar e, em seguida, sai da boca, a parte anterior da língua tocando com sua porção sublaminal o lábio inferior e quase tocando a parte superior do queixo com a sua ponta" (Everett, op. cit., 94); $2^{\circ}$ ) [5] é caracterizado por Everett (op. cit.) como uma vibrante bilabial vozeada.

Everett (op. cit.) conclui que no Pirahã traços sociais são obrigatórios nas regras fonológicas para prever a realização fonética, uma vez que a distribuição de [1] e [ந్ ] restringe-se às mulheres, na maioria dos casos. Os homens só os empregarão em situações especificadas pelo traço [+familiar], que permite seu uso. Assim, na matriz fonética confeccionada pelo autor, há a inclusão do traço [superstrato] para distinguir os fones [1] e [б] de todos os demais, consonantais ou vocálicos (cf. Everett, op. cit., 100).

\section{XAVANTE}

Lachnitt (1988) registra algumas oposições entre a fala feminina e a masculina na língua Xavante, da família Jê, falada no Brasil, no que se refere a pronomes e advérbios, que podem ser assim resumidas.

(18) diferenças quanto ao emprego de pronomes indefinidos

fala feminina fala masculina

tiha $\quad$ mar que, o que, a coisa, qualquer coisa

tiha niha como, algo 
112

(19) diferenças quanto ao uso de pronomes interrogativos

$\begin{array}{lll}\text { fala feminina } & \text { fala masculina } \\ \text { e tiha } & \text { e mar } & \text { o que? } \\ \text { e tiha } & \text { e niha } & \text { como? }\end{array}$

(20) diferenças quanto ao emprego de advérbio de negação

fala feminina fala masculina

madze di mare di não tem, nada

\section{À GUISADE CONCLUSÃO}

Em muitas línguas do mundo, em maior ou menor grau, existem diferenças sistemáticas entre as falas do homem e da mulher, diferenças estas que se evidenciam nos diversos níveis, tais como na fonologia, como é o caso do Karajá, e na morfologia, como no Kamaiurá. Há também línguas em que as diferenças entre as duas falas acontecem em mais de um nível. Essa diferença, portanto, não é nada exótica, e não se restringe às línguas indígenas. Confira-se, por exemplo, o Japonês. Portanto, as línguas que foram apresentadas neste artigo não se constituem em exceções, como crêem muitos. Várias línguas indígenas das Américas, como Chiquito, Chukchi, Gros Ventre, Koasati e Yana, possuem essa distinção e, evidentemente, fazem parte de um universo maior de línguas que diferenciam as falas feminina e masculina, ou seja, que expressam um relacionamento intrínseco entre sexo e formas lingüísticas a serem utilizadas. No Brasil há ainda outras línguas indígenas que possuem essa distinção, como o Aweti, do Tronco Tupi (Borella, 2000), e o Apinajé, do Tronco Macro-Jê (Francisco Edviges Albuquerque, em comunicação pessoal), mas, infelizmente, esse é um aspecto ainda pouco pesquisado e conhecido em nossas línguas.

\section{REFERÊNCIAS BIBLIOGRÁFICAS}

BALMORI, C. H. (1967). Estudios de Área Lingüística Indígena. Buenos Aires: Universidad de Buenos Aires, Bucca.

BODINE, A. (1991). Sexocentrismo e pesquisas lingüísticas. In V. Aebischer \& C. Forel (orgs.) Falas masculinas, falas femininas? Sexo e linguagem. São Paulo: Brasiliense, pp. 35- 62.

BORELLA, C.C. (2000). Aspectos morfossintáticos da língua Aweti (Tupi). Dissertação de Mestrado em Lingüística. Campinas: Unicamp.

BORGES, M. V. (1997). As falas feminina e masculina no Karajá. Dissertação de Mestrado em Letras e Lingüística. Goiânia: UFG.

DOBSON, R. M. (1988) Aspectos da língua Kayabi. Série Lingüística nº 12. Brasília: SIL. 
EVERETT, D. L. (1979). Aspectos da fonologia do Pirahã. Dissertação de Mestrado em Lingüística. Campinas: Unicamp.

JESPERSEN, O. (1921). Language. Its nature, development and origin. New York: The Norton Library, W.W. Norton and Company.

LACHNITT, G. (1988). Damreme 'uwaimramidzé. Estudos sistemáticos e comparativos de gramática Xavante (Ed. Experimental). Campo Grande: Missão Salesiana de Mato Grosso.

RODRIGUES, A. D. (1986). Línguas brasileiras. Para o conhecimento das línguas indígenas. São Paulo: Edições Loyola.

SEKI, L. (2000). Gramática do Kamaiurá. Língua Tupi-Guarani do Alto Xingu. Campinas: Editora da Unicamp; São Paulo: Imprensa Oficial. 